\title{
Zinc Prevents the Development of Diabetic Cardiomyopathy in $\mathrm{db} / \mathrm{db}$ Mice
}

\author{
Shudong Wang ${ }^{1,2,+}$, Bowei Wang ${ }^{2,3,+}$, Yuehui Wang ${ }^{1, *}$, Qian Tong ${ }^{1}$, Quan Liu ${ }^{1}$, Jian Sun ${ }^{1}$, \\ Yang Zheng ${ }^{1, *}$ and Lu Cai ${ }^{2,4}$ \\ 1 Cardiovascular Center \& Geriatric Medicine, The First Hospital of Jilin University, Changchun 130021, \\ Jilin, China; wangshudong816@163.com (S.W.); tongqian@126.com (Q.T.); liuquan@jlu.edu.cn (Q.L.); \\ sunjian@163.com (J.S.) \\ 2 Pediatric Research Institute, The Department of Pediatrics, University of Louisville, Louisville, KY 40202, \\ USA; wangbw@jlu.edu.cn (B.W.); 10cai001@louisville.edu (L.C.) \\ 3 Gynecology and Obstetrics, The Second Hospital of Jilin University, Changchun 130041, Jilin, China \\ 4 Wendy Novak Diabetes Care Center, Departments of Pharmacology and Toxicology, University of Louisville, \\ Louisville, KY 40202, USA \\ * Correspondence: yuehuiwang300@hotmail.com (Y.W.); zhengyang@jlu.edu.cn (Y.Z.); \\ Tel.: +86-431-887-82432 (Y.W.); +86-431-887-82217 (Y.Z.) \\ + These authors contributed equally to this work.
}

Academic Editor: Giovanni Tarantino

Received: 27 January 2017; Accepted: 26 February 2017; Published: 7 March 2017

\begin{abstract}
Diabetic cardiomyopathy (DCM) is highly prevalent in type 2 diabetes (T2DM) patients. Zinc is an important essential trace metal, whose deficiency is associated with various chronic ailments, including vascular diseases. We assessed T2DM B6.BKS(D)-Leprdb/J (db/db) mice fed for six months on a normal diet containing three zinc levels (deficient, adequate, and supplemented), to explore the role of zinc in DCM development and progression. Cardiac function, reflected by ejection fraction, was significantly decreased, along with increased left ventricle mass and heart weight to tibial length ratio, in $\mathrm{db} / \mathrm{db}$ mice. As a molecular cardiac hypertrophy marker, atrial natriuretic peptide levels were also significantly increased. Cardiac dysfunction and hypertrophy were accompanied by significantly increased fibrotic (elevated collagen accumulation as well as transforming growth factor $\beta$ and connective tissue growth factor levels) and inflammatory (enhanced expression of tumor necrosis factor alpha, interleukin-1 $\beta$, caspase recruitment domain family member 9 , and B-cell lymphoma/leukemia 10, and activated p38 mitogen-activated protein kinase) responses in the heart. All these diabetic effects were exacerbated by zinc deficiency, and not affected by zinc supplementation, respectively. Mechanistically, oxidative stress and damage, mirrored by the accumulation of 3-nitrotyrosine and 4-hydroxy-2-nonenal, was significantly increased along with significantly decreased expression of Nrf2 and its downstream antioxidants (NQO-1 and catalase). This was also exacerbated by zinc deficiency in the $\mathrm{db} / \mathrm{db}$ mouse heart. These results suggested that zinc deficiency promotes the development and progression of DCM in T2DM db/db mice. The exacerbated effects by zinc deficiency on the heart of $\mathrm{db} / \mathrm{db}$ mice may be related to further suppression of Nrf2 expression and function.
\end{abstract}

Keywords: diabetic cardiomyopathy; zinc supplement; nuclear factor-erythroid 2-related factor 2; inflammation; oxidative stress

\section{Introduction}

Diabetic cardiomyopathy (DCM) is highly prevalent in asymptomatic type 2 diabetes (T2DM) patients. Diabetes is associated with an increased risk of developing heart failure; indeed, 
$75 \%$ of patients with unexplained idiopathic dilated cardiomyopathy were found to be diabetic [1]. Metabolic abnormalities, including hyperglycemia, hyperinsulinemia, and hyperlipidemia, can lead to cellular alterations such as myocardial fibrosis and/or myocardial hypertrophy, and, eventually, DCM. Several studies, mainly echocardiographic and population-based studies, have documented a uniform association of DCM with cardiac hypertrophy and myocardial stiffness, independently of hypertension. The mechanisms underlying the pathophysiology of this disease are not completely elucidated.

It is well known that oxidative stress and inflammation are involved in the pathogenesis of cardiovascular diseases [2]. Extensive research in the past two decades has revealed the mechanism by which continued oxidative stress causes chronic inflammation, which in turn mediates most chronic diseases, including cancer and diabetes, as well as cardiovascular, neurological, and pulmonary ailments. Oxidative stress can activate a variety of transcription factors, including nuclear factor-erythroid 2-related factor 2 (Nrf2) [2,3]. Nrf2 plays an important role in preventing oxidative damage, which contributes to cardiac inflammation. The role of Nrf2 in preventing diabetes-induced oxidative stress is also established. First, Nrf2 is quickly up-regulated in tissues or cells in response to hyperglycemia or high glucose levels [4,5]. Second, diabetes-induced cardiac and renal damage is more severe in Nrf2 gene knockout mice than in wild-type (WT) counterparts [4,6,7]. Third, Nrf2 activation by sulforaphane in vitro and in vivo or MG132 in vivo suppresses high glucose-induced ROS production and metabolic dysfunction in human microvascular endothelial cells [8] and attenuates diabetic proteinuria in streptozotocin (STZ)-induced diabetic rats $[9,10]$. Sulforaphane treatment that activates renal Nrf2 function induces renal protection only in WT mice, not in animals with Nrf2 gene deletion [10].

Zinc $(\mathrm{Zn})$ is an important essential trace metal, a deficiency of which promotes the development of cardiovascular diseases in humans [11]. Studies assessing animal models have also found an association between $\mathrm{Zn}$ deficiency and various vascular diseases [11,12]. Increasing evidence from human and animal studies shows an effect of $\mathrm{Zn}$ on diabetic complications, seemingly through Nrf2 induction by $\mathrm{Zn}[13,14]$.

We previously demonstrated that a high-fat diet (HFD) induces a time-dependent obesity as well as obesity-related cardiac hypertrophy, accompanied by increased cardiac inflammation and p38 MAPK activation. Zn supplementation alleviates, while its deficiency heightens cardiac hypertrophy in HFD-induced obese mice, by suppressing p38 MAPK-dependent cardiac inflammatory and hypertrophic pathways [15]. We also demonstrated that $\mathrm{Zn}$ protects against T1DM-induced damage to the kidney, liver, and testis, mainly by increasing insulin-like function and reducing oxidative stress and inflammation [16,17]. However, whether $\mathrm{Zn}$ has similar effects on the heart in T2DM remains unclear.

In the present study, therefore, we tested the following hypotheses: (1) Zn deficiency may accelerate the development and progression of DCM in T2DM; (2) mechanistically, Zn deficiency may impair the expression and function of Nrf2, leading to an exacerbation of diabetes-induced pathogenic process in cardiomyopathy. Because the effects of $\mathrm{Zn}$ on leptin expression have been extensively reported [18,19], we asked whether Zn deficiency exacerbates and its supplementation attenuates HFD/obesity-induced cardiac alterations by reducing or increasing leptin levels. To this end, T2DM B6.BKS(D)-Leprdb/J ( $\mathrm{db} / \mathrm{db}$ ) mice with leptin receptor deletion were used to rule out the potential effect of $Z n$ deficiency and supplementation on obesity-induced cardiac pathogenesis via systemic leptin signaling. In addition, whether the exacerbated or inhibitory effects of $\mathrm{Zn}$ deficiency and supplement on the heart are related to HFD components remains unclear. Consequently, we did not include HFD since $\mathrm{db} / \mathrm{db}$ mice still develop obesity on a normal diet; this approach would eliminate the potential direct effects of HFD-contained components on the heart. 


\section{Results}

\subsection{General Features of $d b / d b$ Mice after Treatment with Different Zn Amounts}

Mice were fed normal diet with different amounts of $\mathrm{Zn}$, including $\mathrm{Zn}$ deficient (ZD), Zn adequate $(\mathrm{ZN})$, Zn supplemented (ZS), and ZS for the first three months and switched to ZN (ZS-N) groups, starting at the age of 17 weeks. Non-fasting blood glucose levels (Figure 1A) and blood GHbA1c (Figure 1B) were increased in $\mathrm{db} / \mathrm{db}$ mice compared with WT animals. Insulin resistance was assessed by intraperitoneal glucose tolerance test (IPGTT) with injection of $2 \mathrm{~g} / \mathrm{kg}$ body weight, and blood glucose was assessed at the six month time point (Figure 1C), followed by AUC determination (Figure 1D). db/db mice showed significantly increased IPGTT, as reflected by elevated AUCs at six months (Figure 1C,D). Interestingly, ZD worsened the $\mathrm{db} / \mathrm{db}$ mouse condition, further increasing non-fasting blood glucose levels, blood GHbA1c, and IPGTT, while ZS and ZS-N showed no significant changes compared with the ZN group. Calorie intake was not significantly changed based on daily food consumption.

A

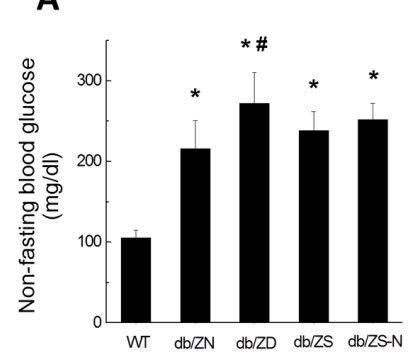

c

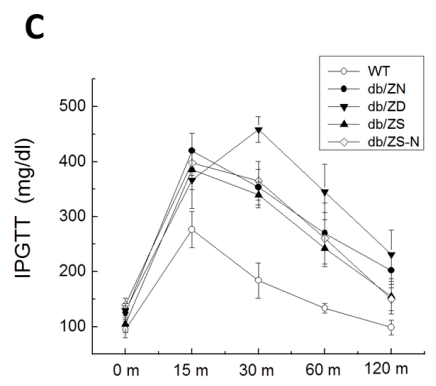

B

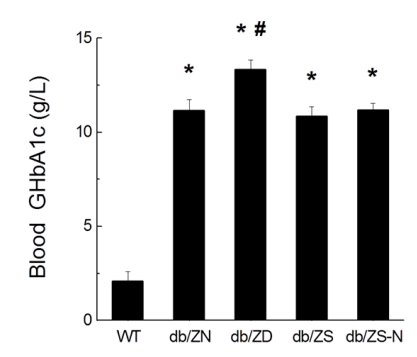

D

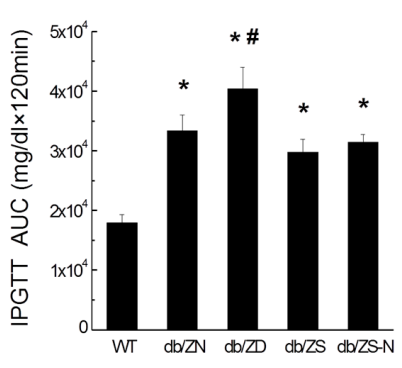

$\mathbf{E}$

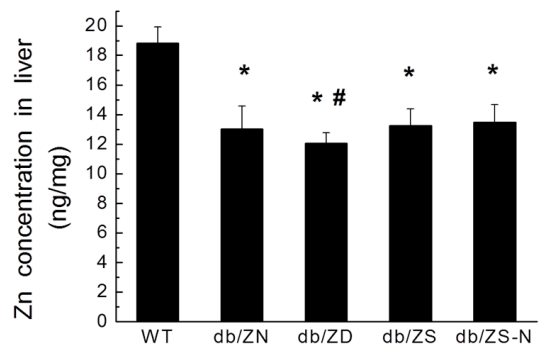

Figure 1. Systemic effects of different $\mathrm{Zn}$ amounts in $\mathrm{db} / \mathrm{db}$ mice. Twenty-one B6.BKS(D)-Leprdb/J mice were randomly divided into four groups and fed normal chow (10\% Cal from fat) with different amounts of Zn (ZD, ZN, ZS and ZS-N, respectively); seven C57BL/6J mice were fed ZN as the control group (WT). All mice were fed from the age of 17 weeks, and sacrificed six months later (as $6 \mathrm{M}$ ). Non-fasting glucose levels (A) and blood GHbA1c (g/L) (B) were evaluated. IPGTT (C) at six months and related area under curve (AUC) values (D) were assessed. Zn levels in the liver were measured in WT and diabetic mouse groups (E). Data were presented as mean $\pm \mathrm{SD}(n=7$ for WT control and $\mathrm{db} / \mathrm{db}-\mathrm{ZD}(\mathrm{db} / \mathrm{ZD})$ groups; $n=6$ for $\mathrm{db} / \mathrm{db}-\mathrm{ZN}(\mathrm{db} / \mathrm{ZN})$ group; $n=4$ for $\mathrm{db} / \mathrm{db}-\mathrm{ZS}(\mathrm{db} / \mathrm{ZS})$ and $\mathrm{db} / \mathrm{db}-\mathrm{ZS}-\mathrm{N}$ (db/ZS-N) groups). Differences were assessed by ANOVA with Tukey-Kramer post hoc analysis. ${ }^{*}, p<0.05$ vs. WT group; $\#, p<0.05$ vs. $\mathrm{db} / \mathrm{ZN}$ group. 


\subsection{Zn Levels in Cardiac and Liver Tissues}

Because cardiac tissue and serum specimens were limited, we measured hepatic $\mathrm{Zn}$ levels. As shown in Figure 1E, hepatic $\mathrm{Zn}$ levels in $\mathrm{db} / \mathrm{db}$ mice were decreased significantly compared with the amounts of WT mice. Compared with the ZN group, the ZD group showed further decreased levels of hepatic Zn, while no significant change was found in the ZS and ZS-N groups.

\subsection{Cardiac Hypertrophy and Function}

Echocardiographic analysis showed that $\mathrm{EF} \%$ (Figure $2 \mathrm{~A}$ ) in $\mathrm{db} / \mathrm{db}$ mice decreased significantly, with markedly increased LV mass (Figure 2B) and heart weight to tibial length ratio (Figure 2C). ANP protein expression levels were significantly higher in $\mathrm{db} / \mathrm{db}$ mice than in WT animals (Figure 2D). All these parameters were significantly worsened by ZD, compared with the ZN group, but not significantly changed in the ZS and ZS-N groups.

A

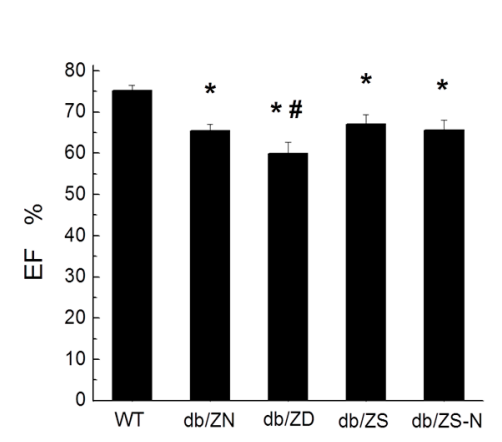

C

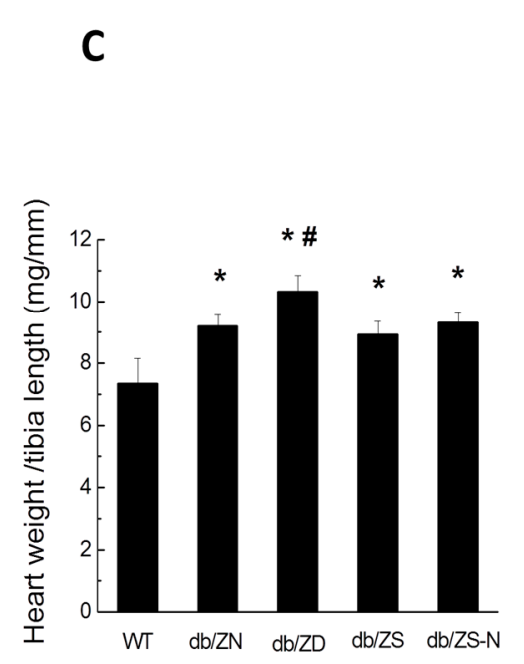

B

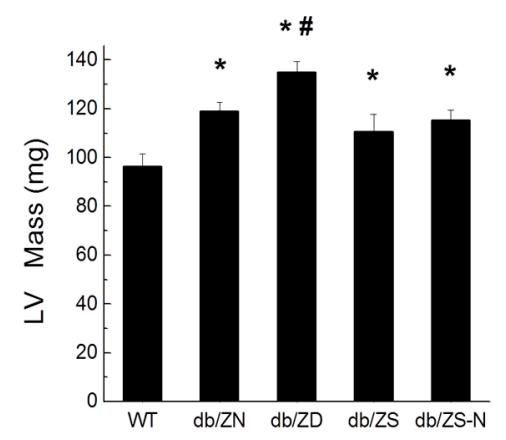

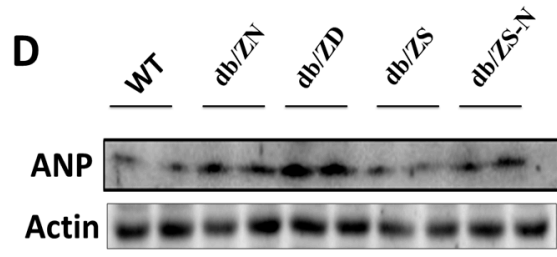

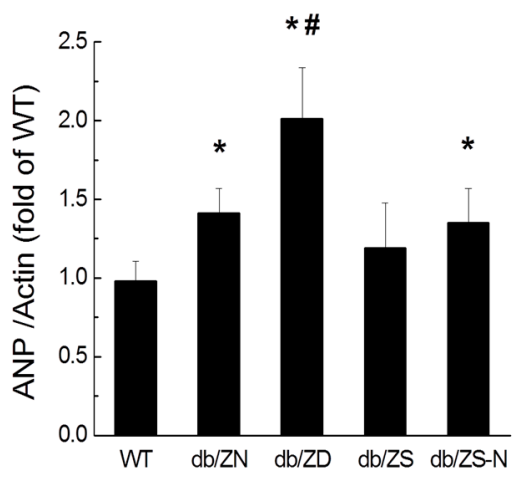

Figure 2. Zn deficiency exacerbates diabetic-induced heart hypertrophy and function. Animals were treated as described in Figure 1. EF\% (A) and corrected Left ventricular (LV) mass (mg/g) (B) were examined by echocardiography. Heart-weight to tibial length ratio (C) and atrial natriuretic peptide (ANP) protein levels obtained by Western Blot (D) were assessed as indicators of heart hypertrophy and function. Data were presented as mean $\pm \mathrm{SD}(n=4-7$, details in Figure 1$){ }^{*}, p<0.05$ vs. WT group; $\#, p<0.05$ vs. $\mathrm{db} / \mathrm{ZN}$ group. 


\subsection{Zn Prevents Cardiac Fibrosis in db/db Mice}

Sirius Red Staining followed by semi-quantitative analysis (Figure $3 \mathrm{~A}$ ) indicated increased fibrosis in all four $\mathrm{db} / \mathrm{db}$ groups compared with WT controls. Among the $\mathrm{db} / \mathrm{db}$ mice, the $\mathrm{db} / \mathrm{db}-\mathrm{ZD}$ group had worse outcome compared with db/db-ZN animals, while the ZS and ZS-N groups showed no significant change in terms of cardiac fibrosis severity compared to the $\mathrm{ZN}$ group. Western blot demonstrated that TGF- $\beta$ and CTGF amounts in the diabetic groups were significantly higher compared with WT group levels (Figure 3B). Meanwhile, db/db-ZD animals had significantly higher expression levels of TGF- $\beta$ and CTGF compared with the $\mathrm{db} / \mathrm{db}-\mathrm{ZN}$ group. However, the ZS, ZN and ZS-N groups showed similar TGF- $\beta$ and CTGF levels.

A

WT

$\mathrm{db} / \mathrm{ZN}$

Sirius

Red

Staining

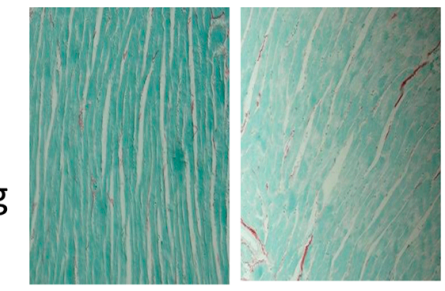

$\mathrm{db} / Z \mathrm{D}$

$\mathrm{db} / \mathrm{ZS}$

$\mathrm{db} / \mathrm{ZS}-\mathrm{N}$
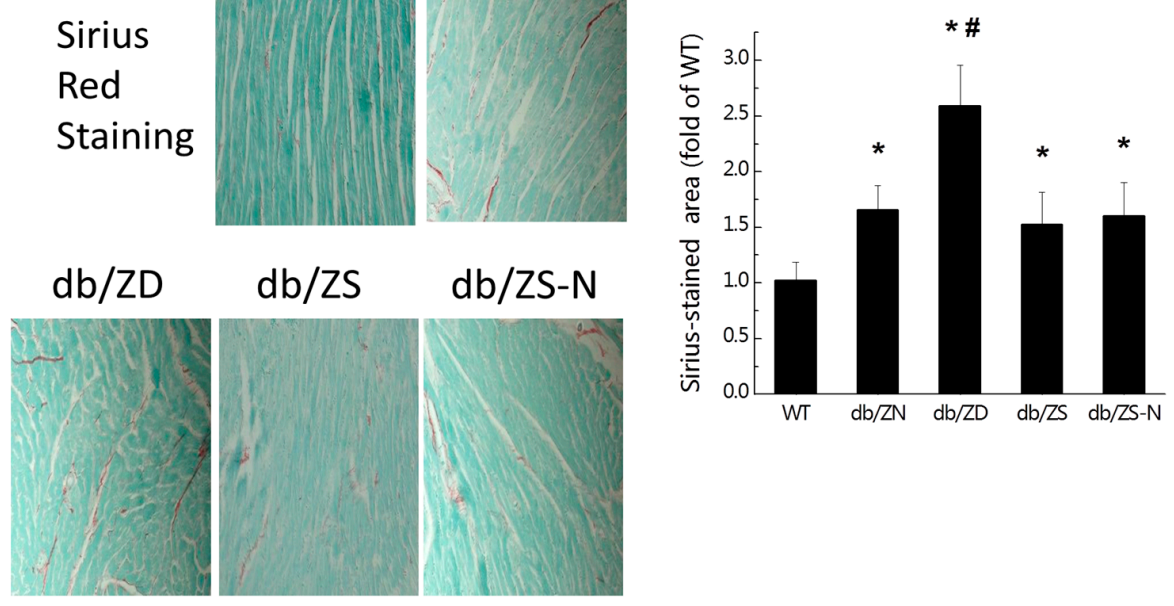

B
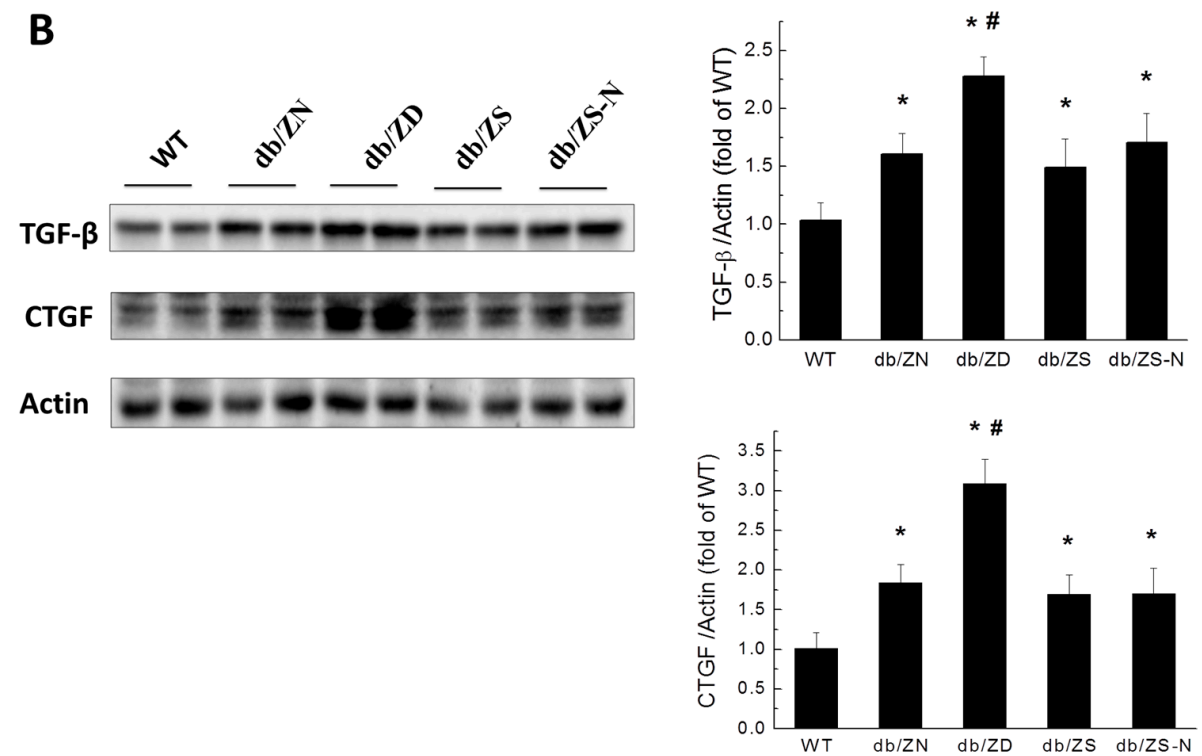

Figure 3. Zn deficiency exacerbates diabetes-induced cardiac fibrosis. Sirius Red Staining (A) was used to assess fibrosis in the heart, Scale bar $=25 \mu \mathrm{M}$. Western blot was used to evaluate fibrosis related factors (B), including transforming growth factor $\beta$ (TGF- $\beta$ ) and connective tissue growth factor (CTGF). Data were presented as mean $\pm \mathrm{SD}\left(n=4-7\right.$, details in Figure 1). ${ }^{*}, p<0.05$ vs. WT group; $\#, p<0.05 \mathrm{vs} . \mathrm{db} / \mathrm{ZN}$ group. 


\subsection{Zn Prevents Cardiac Inflammation in $\mathrm{db} / \mathrm{db}$ Mice}

Given that hyperglycemia induces chronic inflammation as a causative factor of cardiac remodeling, the expression levels of inflammatory markers, including p-P38, p38, TNF- $\alpha$, IL-1 $\beta$ (Figure 4A), CARD9, and BCL10 (Figure 4B), were examined by Western blot. Interestingly, diabetic mice showed significantly increased expression levels of these proteins in cardiomyopathy at the $6 \mathrm{M}$ time-point; these changes were even more notable in the ZD group. However, Zn supplementation (ZS and ZS-N) alleviated these effects, and the amounts of the above inflammatory factors were similar to $\mathrm{ZN}$ group values.
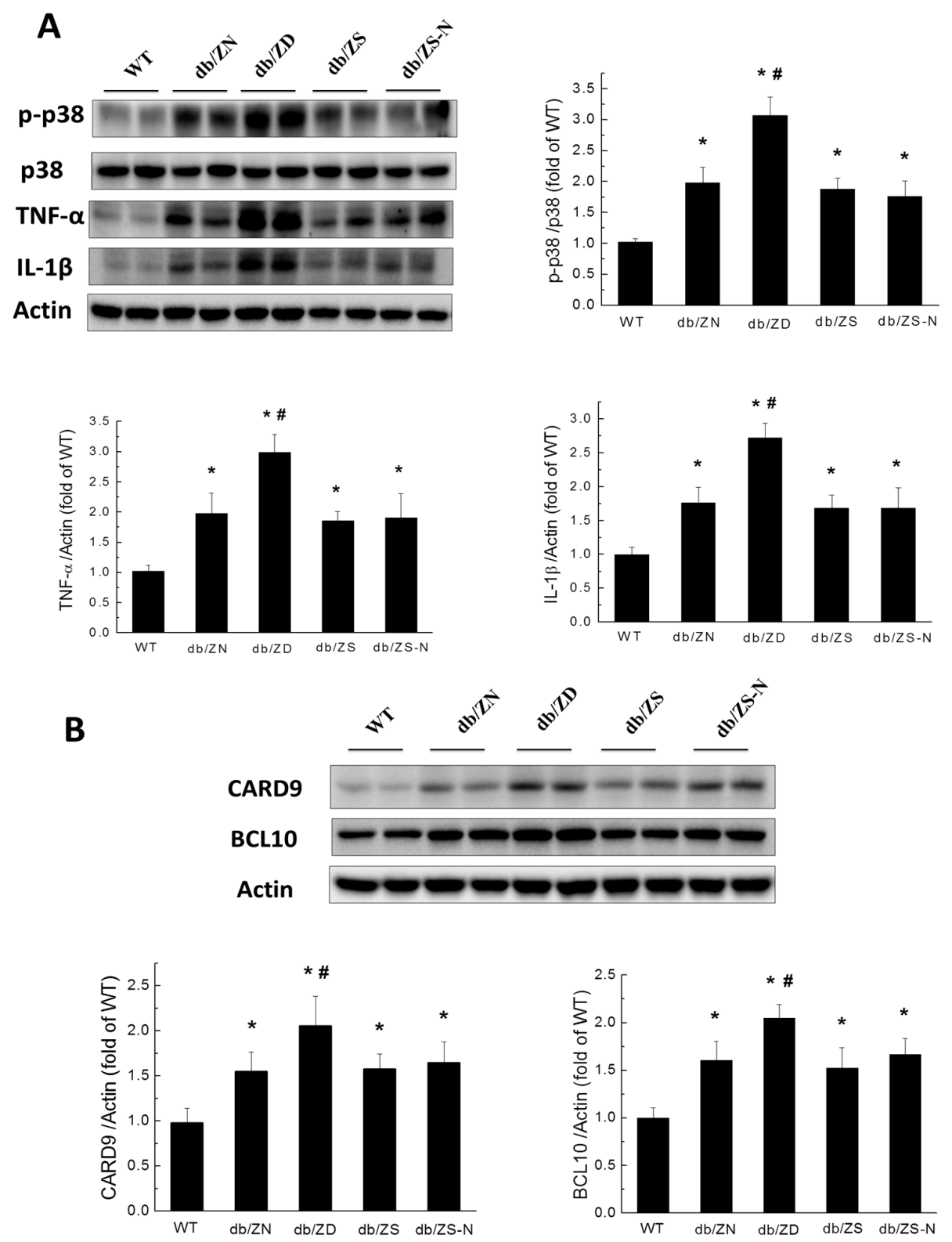

Figure 4. Zn deficiency exacerbates diabetes-induced cardiac inflammation. Western blot was used to assess fibrosis-related factors such as p-P38/p38, TNF- $\alpha$, IL-1 $\beta$ (A), CARD9, and BCL10 (B). Data were presented as mean \pm SD $(n=4-7$, details in Figure 1); differences were assessed by ANOVA with Tukey-Kramer post hoc analysis. ${ }^{*}, p<0.05$ vs. WT group; $\#, p<0.05$ vs. db $/ \mathrm{ZN}$ group. 
2.6. Zn Attenuation of Cardiac Oxidative Stress Is Probably Associated with Nrf2 Activation to Upregulate Downstream Antioxidants

Considering that inflammation is often accompanied by oxidative stress, such damage was evaluated by Western blot for 3-NT (Figure 5A) and 4-HNE (Figure 5B); significantly increased amounts of these proteins were found in diabetic mice at the $6 \mathrm{M}$ time-point. ZD exacerbated cardiac oxidative stress in diabetic mice, while the ZS and ZS-N groups showed 3-NT and 4-HNE levels similar to $\mathrm{ZN}$ group values.

A

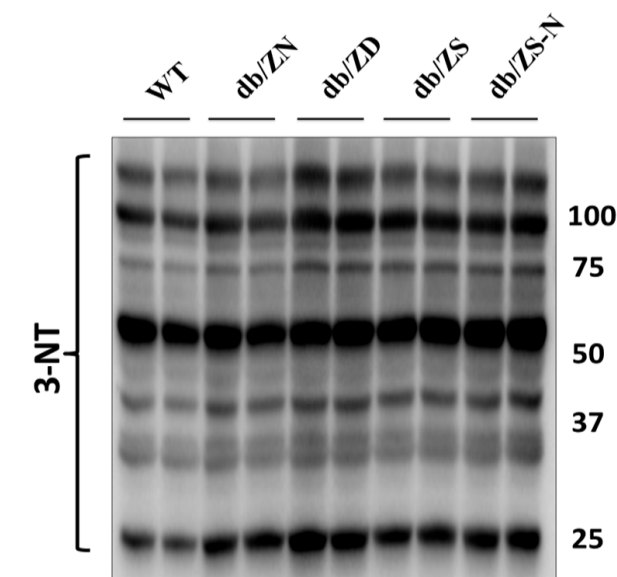

Actin
B

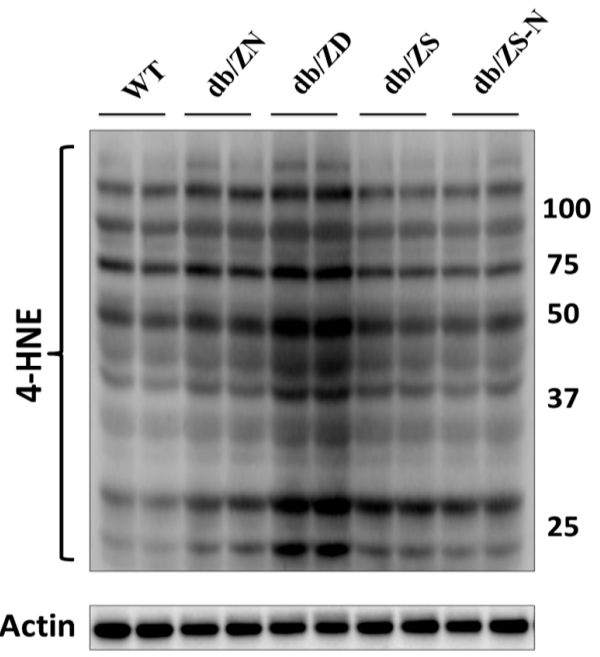

Actin
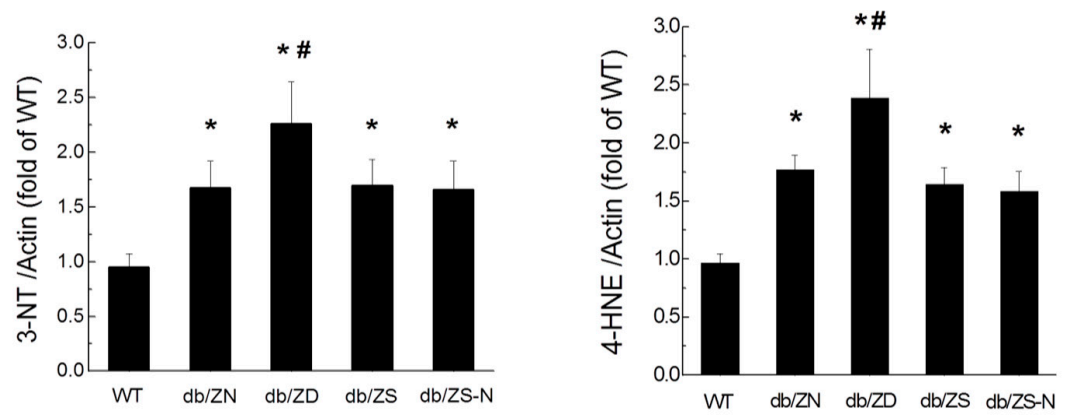

Figure 5. Zn exacerbates diabetes-induced cardiac oxidative damage. Oxidative damage was examined by Western blot for 3-NT (A) and 4-HNE (B) accumulation in the myocardium, followed by quantitative analysis. 3-NT includes all nitrated tyrosine containing proteins (A). Similarly, 4-HNE includes all proteins containing 4-hydroxy-2-nonenal (a peroxide lipid) (B). All bands were quantified. Data were presented as mean $\pm \mathrm{SD}(n=4-7$, details in Figure 1$) .{ }^{*}, p<0.05$ vs. WT group; $\#, p<0.05$ vs. $\mathrm{db} / \mathrm{ZN}$ group.

To explore the mechanism behind the protective effects of $\mathrm{Zn}$ toward diabetic-induced pathological changes in the mouse heart, nuclear transcription factor (Nrf2) expression was analyzed at the protein and gene levels, respectively, by Western blot and RT-PCR. Western blot showed that db/db mice displayed significantly decreased amounts of Nrf2 and the downstream catalase (CAT) and NQO1 proteins in cardiac tissues. Zn deficiency aggravated these changes, while the ZS and ZS-N groups showed similar protein levels of Nrf2, CAT, and NQO1 to the ZN group (Figure 6A). At the 
transcriptional level, mRNA amounts of Nrf2, catalase and NQO-1 were significantly decreased in diabetic mice of the ZD group, while the ZS and ZS-N groups showed increased mRNA levels of these genes (Figure 6B).
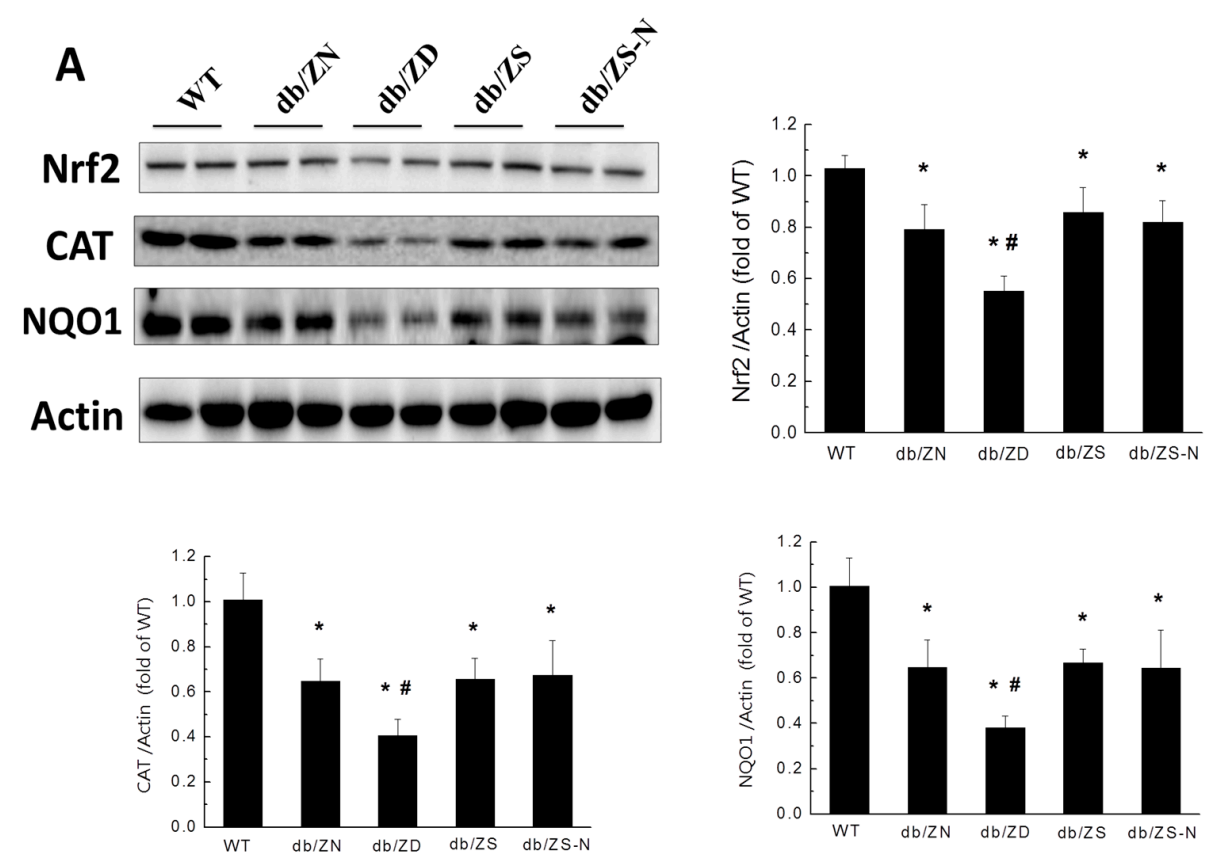

B
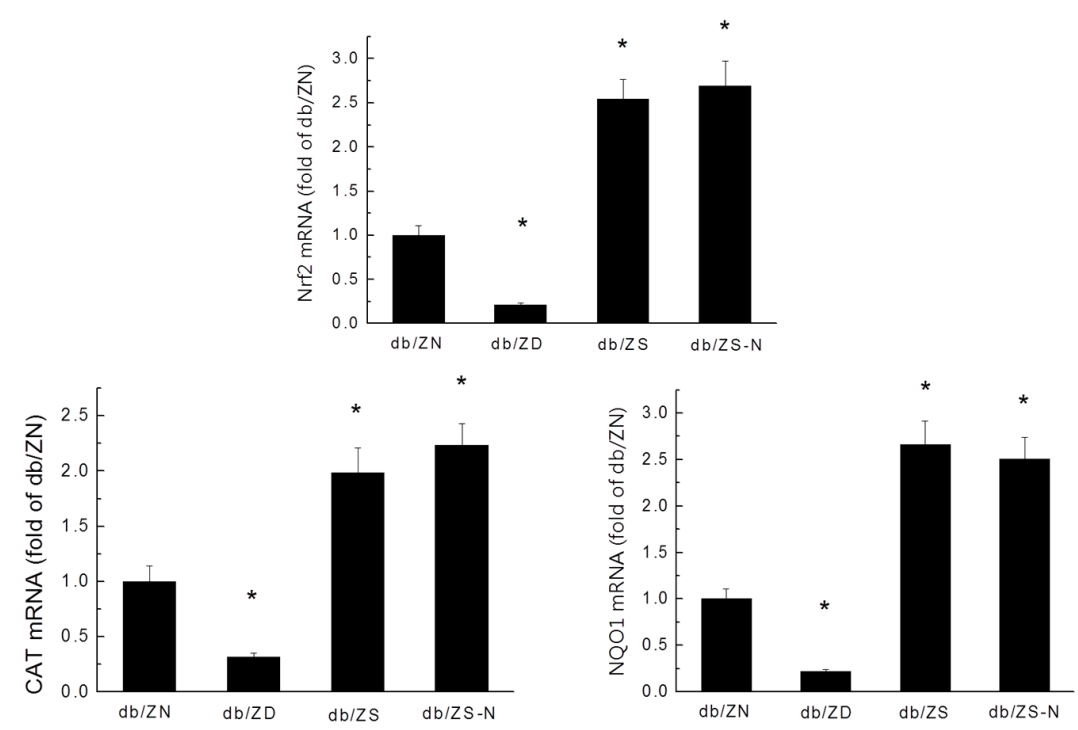

Figure 6. Effects of Zn deficiency and supplementation on T2DM-induced downregulation of Nrf2 and downstream genes in $\mathrm{db} / \mathrm{db}$ mice. The expression levels of Nrf2 protein and downstream factors, such as catalase and $\mathrm{NAD}(\mathrm{P}) \mathrm{H}$ dehydrogenase 1 ( NQO-1), were examined by Western blot (A) and RT-PCR (B). Data were presented as mean $\pm \operatorname{SD}(n=4-7$, details in Figure 1$) .{ }^{*}, p<0.05$ vs. WT group; $\#, p<0.05$ vs. $\mathrm{db} / \mathrm{ZN}$ group.

\section{Discussion}

Both diabetes and $\mathrm{Zn}$ deficiency are global health problems $[1,11,20]$. Diabetic patients often suffer from $\mathrm{Zn}$ deficiency at the late disease stage, particularly those whose glucose is poorly controlled [21-24]. Zn supplementation has beneficial effects on glucose and lipid control [25]. In the present study, an animal model of T2DM with leptin receptor defect was used to demonstrate 
that Zn deficiency significantly exacerbates obesity-induced cardiac oxidative damage, inflammation, and fibrosis in diabetes, effects associated with significantly decreased expression of Nrf2 and the downstream antioxidants NQO- 1 and CAT. These changes were exacerbated by Zn deficiency, but not affected by $\mathrm{Zn}$ supplementation in $\mathrm{db} / \mathrm{db}$ mice. As an adaptive mechanism, Nrf2 is quickly upregulated in cells and tissues in response to various oxidative stresses, but downregulated at late stage after exposure to chronic oxidative stress [17,26-28]. In the current study, cardiac Nrf2 expression levels were decreased in diabetic mice after six months on HFD, probably because the diabetes duration was long enough. Moreover, diabetic mice with Zn deficiency showed further downregulation of Nrf2 and the downstream effectors NQO-1 and catalase. More importantly, Zn deficiency-exacerbated Nrf2 downregulation resulted in severely increased oxidative damage, cardiac inflammation, and fibrosis. Meanwhile, an important finding was that $\mathrm{Zn}$ deficiency aggravated diabetes-induced pathogenic changes, in association with further Nrf2 downregulation in the T2DM model.

Multiple pathways have been linked to hyperglycemia-induced oxidative stress, inflammation, fibrosis, and cardiovascular diseases. T2DM has been experimentally characterized by myocardial inflammation, including increased TNF- $\alpha$ expression, oxidative stress, and fibrosis [29]. Phosphor-p38 MAPK upregulation was reported to contribute to cardiac hypertrophy in obese [15] and T2DM [30,31] animals. BCL10 reportedly binds CARD9 to activate NF- KB [32]. BCL10 deletion resulted in reduced cardiac remolding induced by angiotensin II [33]; similarly, CARD9 deletion also ameliorated obese-induced cardiac dysfunction [31].

However, other studies demonstrated that CARD9 mediates the activation of p38 MAPK, which is pivotal in multiple immune responses and inflammation activation [34-36]. CARD9 signaling allows Toll like receptor (nucleotide-binding oligomerization domain) pathways to induce p38 MAPK activation [34,37]. Previous studies reported that CARD9 knockout attenuates cardiac dysfunction by abrogating increased p38 MAPK phosphorylation in obese mice, as well as cardiac inflammation and fibrosis after angiotensin II treatment [31,38]. The present study demonstrated that $\mathrm{Zn}$ deficiency exacerbated BCL10 and CARD9 expression changes in $\mathrm{db} / \mathrm{db}$ mice, although there were no significant differences among the ZN, ZS, and ZS-N groups.

Our team and others have reported that overexpression of metallothionein, catalase, and manganese superoxide dismutase in the heart reverses diabetic cardiomyopathy in animal models of both T1DM and T2DM [39-42]. Thus, strategies that either reduce ROS or augment myocardial antioxidant defense mechanisms might have therapeutic efficacy in improving myocardial function in diabetes. As shown above, $\mathrm{db} / \mathrm{db}$ mice displayed significantly decreased levels of Nrf2 and downstream antioxidants, including catalase, compared with WT control mice. Among the $\mathrm{db} / \mathrm{db}$ mice, the expression levels of Nrf2 and downstream antioxidants were lowest in the ZD group, which may be the main reason why Zn deficiency exacerbates obesity/T2DM-induced cardiac remodeling and dysfunction. Indeed, low antioxidant capacity may lead to high oxidative stress that induces BCL10/CARD9-mediated p38 MAPK activation, resulting in cardiac inflammation and remodeling, and even dysfunction. In addition, since the ZD group also showed worst outcomes of blood glucose and GHbA1c levels as well as insulin resistance, the worsening effects of ZD on these systemic alterations may also be in part responsible for the aggravated development of DCM.

It should be mentioned that, in the present study, $\mathrm{Zn}$ supplementation to $\mathrm{db} / \mathrm{db}$ mice did not exert any beneficial effects on T2DM-induced-cardiac pathogenesis compared to the ZN group. In contrast, we recently demonstrated that HFD induces cardiac hypertrophy along with inflammation, which were exacerbated and attenuated by Zn deficiency and supplementation, respectively, compared with ZN groups, in HFD-induced obese WT mice [15]. The discrepancy between the two studies suggests that Zn supplementation-mediated cardiac protection from obesity and/or T2DM is likely dependent on leptin-mediated signaling, as shown by the impact of $\mathrm{Zn}$ on leptin levels [18,19]; this will be further explored in future studies. 


\section{Materials and Methods}

\subsection{Animals}

B6.BKS(D)-Leprdb/J (db/db) and C57BL/6J mice were obtained from the Jackson Laboratory (Bar Harbor, ME, USA), and housed in the University of Louisville Research Resources Center at $22{ }^{\circ} \mathrm{C}$ under a 12:12 h light/dark cycle, with tap water and rodent diet ad libitum. All experimental procedures were approved by the Institutional Animal Care and Use Committee of the University of Louisville (3 April 2015), and carried out in accordance with the Guide for the Care and Use of Laboratory Animals, Eighth Edition (Library of Congress Control Number: 2010940400, revised 2011). Twenty-one B6.BKS (D)-Leprdb/J mice were randomly divided into four groups. The first 17 mice were fed a normal diet (10\% calories from fat) with different amounts of Zn, including $10 \mathrm{mg}$ (deficient, ZD; $n=7$ ), $30 \mathrm{mg}$ (adequate, $\mathrm{ZN} ; n=6$ ), and $90 \mathrm{mg}$ (supplemented, ZS; $n=4$ ) per $4057 \mathrm{Kcal}$, respectively, for six months. The fourth group of four $\mathrm{db} / \mathrm{db}$ mice were fed $\mathrm{ZS}$ for the first three months and switched to $\mathrm{ZN}$ for the subsequent three months, the same as the $\mathrm{db} / \mathrm{db} / \mathrm{ZS}-\mathrm{N}$ group. Meanwhile, seven C57BL/6J mice were fed a ZN diet for six months as a control group. After six months, all mice were sacrificed at $6 \mathrm{M}$.

\subsection{Intraperitoneal Glucose Tolerance Test (IPGTT)}

Insulin resistance was assessed by IPGTT [43]. Briefly, mice were fasted for $6 \mathrm{~h}$ (8:00 a.m.-2:00 p.m.) and injected intraperitoneally with D-(+)-glucose (Sigma-Aldrich, St. Louis, MO, USA) at a dose of $2 \mathrm{~g} / \mathrm{kg}$ body weight. Blood glucose levels at $0,15,30,60$, and $120 \mathrm{~min}$ after glucose injection were measured using a FreeStyle Lite glucometer (Abbott Diabetes Care, Alameda, CA, USA). Glucose tolerance test area under the curve (AUC) was assessed by the trapezoid rule with the Origin 8.6 software (OriginLab Co., Northampton, MA, USA).

\subsection{Echocardiography for EF\% and LV Mass Assessment}

Transthoracic echocardiography was performed as described previously [44]. Briefly, a highresolution imaging system for small animals (Vevo 770, Visual Sonics, Toronto, Ontario, Canada) equipped with a high-frequency ultrasound probe (RMV-707B) was used. Left ventricular (LV) dimensions, end-diastolic inter-ventricular septum thickness (IVS; d), end-diastolic left ventricular posterior wall thickness (LVPW; d), LV fractional shortening (FS), LV mass, and LV ejection fraction (EF) were measured from LV M-Mode images.

\subsection{Zn Concentration Assessment in the Liver Tissue}

Each liver sample (30 mg wet-weight) was digested with $1 \mathrm{~mL} \mathrm{70 \%} \mathrm{concentrated} \mathrm{nitric} \mathrm{acid,}$ in an $85^{\circ} \mathrm{C}$ water bath for $3 \mathrm{~h}$. After digestion, each sample was diluted 35 times. The digested samples were then filtered using a PTFE $0.2 \mathrm{~mm}$ filter. Liver Zn levels were assessed by Atomic Absorption Spectroscopy (AAS) on an iCE-3000 AAS instrument from Thermo Fisher Scientific (Waltham, MA, USA). Zn levels were calculated based on a standard curve and presented as ng/mg wet tissue.

\subsection{Sirius Red Staining}

Heart fibrosis was assessed by Sirius red staining for collagen, with a mixture of $0.1 \%$ Sirius red F3BA and $0.25 \%$ Fast Green FCF. Collagen amounts in the myocardium were evaluated using Pro Plus 6.0 software (Media Cybernetics Inc., Bethesda, MD, USA).

\subsection{Quantitative Real-Time PCR}

Total RNA was extracted from heart tissues with TRIzol-reagent (RNA STAT60 Tel-Test; Austin, Texas, USA). RNA amounts and purity were determined on a Nanodrop ND-1000 spectrophotometer (Thermo Scientific, Wilmington, DE, USA). Random-primed strand complimentary DNA (cDNA) 
was synthesized from total RNA using GoScript Reverse Transcription System (Promega, Madison, WI, USA) following the manufacturer's instructions. Primers for NQO-1 (Mm01253561_m1), catalase (Mm00437992_m1), Nfe2/2 (Mm00477784_m1), and glyceraldehyde-3-phosphate dehydrogenase (GAPDH, Mm99999915_g1) were purchased from Thermo Fisher Scientific. Quantitative RT-PCR (qRT-PCR) was performed in duplicate in a $20 \mu \mathrm{L}$ reaction system comprising $10 \mu \mathrm{L}$ of TaqMan Universal PCR Master Mix, $1 \mu \mathrm{L}$ of each primer, and $3 \mu \mathrm{L}$ of cDNA, on an ABI 7500 RT-PCR system (Applied Biosystems, Foster City, CA, USA). $C_{t}$ values were obtained, and relative gene expression was assessed by the $2^{-\Delta \Delta C t}$ method, with GAPDH used for normalization.

\subsection{Western Blot}

Heart tissues were homogenized in RIPA lysis buffer (sc-24948A, Santa Cruz Biotech, CA, USA). After centrifugation at $12,000 \mathrm{~g}$ and $4{ }^{\circ} \mathrm{C}$ for $15 \mathrm{~min}$, the supernatants were collected and protein levels determined using the Bradford protein assay (Bio-Rad, Hercules, CA, USA). Tissue lysates were diluted with loading buffer and heated to $95{ }^{\circ} \mathrm{C}$ for $5 \mathrm{~min}$. Then, equal amounts of total protein $(40 \mu \mathrm{g})$ were separated by $10 \%$ SDSPAGE at $120 \mathrm{~V}$ and transferred onto $0.2 \mu \mathrm{m}$ nitrocellulose membranes (162-0112, Bio-Rad) for $1.5 \mathrm{~h}$ at $4{ }^{\circ} \mathrm{C}$. Nonspecific proteins were blocked with $5 \%$ nonfat dried milk and $0.5 \%$ BSA in TBS-T (20 mM Tris- $\mathrm{HCl}$ [pH 7.6], $150 \mathrm{mM} \mathrm{NaCl}$, and $0.1 \%$ Tween 20) for $1 \mathrm{~h}$ at room temperature with agitation. Subsequently, the membranes were incubated with anti-tumor necrosis factor $\alpha$ (TNF- $\alpha$, Abcam, Cambridge, USA, ab6671, 1:1000), anti-connective tissue growth factor (CTGF1, Santa Cruz Biotech., sc-14939, 1:1000), anti-phospho-p38 (Thr180/Tyr1821, Cell Signaling, Danvers, MA, 1:1000) , anti-p38 (Cell Signaling, 1:1000), anti-atrial natriuretic peptide (ANP, Santa Cruz Biotech, 1:1000), anti-interleukin $1 \beta$ (IL-1 $\beta$, Santa Cruz Biotechnology, sc-7884, 1:1000), anti-caspase recruitment domain family member 9 (CARD9, Cell Signaling, \#12283, 1:1000), anti-B-cell lymphoma/leukemia 10 (BCL10, Santa Cruz Biotechnology, sc-5611, 1:1000), anti-3-nitrotyrosine (3-NT, Millipore, 1:3000), anti-4-hydroxy-2-nonenal (4-HNE, Alpha Diagnostic International, San Antonio, TX, USA, 1:3000), and anti- $\beta$-actin (Santa Cruz Biotech., sc1616, 1:3000) primary antibodies overnight at $4{ }^{\circ} \mathrm{C}$. After three washes with TBS-T, the membranes were incubated with HRP-conjugated secondary antibodies (Santa Cruz Biotech) for $1 \mathrm{~h}$ at room temperature. Immunoreactive bands were visualized using an enhanced chemiluminescence (ECL) kit (Bio-Rad), and revealed on a ChemiDoc Touch Imaging System (Bio-Rad). Protein expression levels were normalized to $\beta$-actin as an internal control. For Western blot, aortic tissues were homogenized in a RIPA lysis buffer (sc-24948A, Santa Cruz Biotech.).

\subsection{Statistical Analysis}

Data are mean \pm standard deviation (SD) with 4-7 animals per group. Group comparisons were performed by one-way analysis of variance (ANOVA), followed by pairwise repetitive comparisons with Tukey test, using the Origin 8.0 Lab data analysis and graphing software. $p<0.05$ was considered statistically significant.

\section{Conclusions}

In conclusion, this is the first study to our knowledge providing evidence regarding the relationship between DCM and long-term $\mathrm{Zn}$ treatment in T2DM animal models. We confirmed that $\mathrm{Zn}$ deficiency contributes to the pathological progression of cardiac disorders induced by T2DM, and revealed the partial protective effect of long-term $\mathrm{Zn}$ supplementation on DCM. These findings confirm the significant role of $\mathrm{Zn}$ in preventing diabetic related cardiac disorders in T2DM mouse models. Optimal Zn supplementation dose for T2DM mice could be identified to prevent DCM. Overall, $\mathrm{Zn}$ supplements might be highly potent in the prevention and/or treatment of T2DM related DCM.

Acknowledgments: This work was supported in part by grants from the National Science Foundation of China (81370318 and 81570339 to Yang Zheng; 81670343 to Quan Liu; 81573493 to Qian Tong; 81270293, 81470061 , and 81671378 to Yuehui Wang). Bowei Wang is a recipient of the Chinese Government Scholarship (No. 201506175180). 
Author Contributions: Shudong Wang and Bowei Wang performed the most of research and analyzed experimental data. Qian Tong, Quan Liu and Jian Sun involved in part of the experiments. Bowei Wang, Yang Zheng and Lu Cai contributed to the initial discussion and design of the project. Shudong Wang, Bowei Wang, Yuehui Wang, Yang Zheng and Lu Cai wrote and revised manuscript. All authors have reviewed and commended the final manuscript.

Conflicts of Interest: The authors declare no conflict of interest.

\section{References}

1. Bertoni, A.G.; Tsai, A.; Kasper, E.K.; Brancati, F.L. Diabetes and idiopathic cardiomyopathy: A nationwide case-control study. Diabetes Care 2003, 26, 2791-2795. [CrossRef] [PubMed]

2. Guerrero-Romero, F.; Rodriguez-Moran, M. Hypomagnesemia, oxidative stress, inflammation, and metabolic syndrome. Diabetes Metab. Res. Rev. 2006, 22, 471-476. [CrossRef] [PubMed]

3. Shannahan, J.H.; Schladweiler, M.C.; Richards, J.H.; Ledbetter, A.D.; Ghio, A.J.; Kodavanti, U.P. Pulmonary oxidative stress, inflammation, and dysregulated iron homeostasis in rat models of cardiovascular disease. J. Toxicol. Environ. Health A 2010, 73, 641-656. [CrossRef] [PubMed]

4. He, X.; Kan, H.; Cai, L.; Ma, Q. Nrf2 is critical in defense against high glucose-induced oxidative damage in cardiomyocytes. J. Mol. Cell Cardiol. 2009, 46, 47-58. [CrossRef] [PubMed]

5. Tan, Y.; Ichikawa, T.; Li, J.; Si, Q.; Yang, H.; Chen, X.; Goldblatt, C.S.; Meyer, C.J.; Li, X.; Cai, L.; et al. Diabetic downregulation of Nrf2 activity via ERK contributes to oxidative stress-induced insulin resistance in cardiac cells in vitro and in vivo. Diabetes 2011, 60, 625-633. [CrossRef] [PubMed]

6. Jiang, T.; Huang, Z.; Lin, Y.; Zhang, Z.; Fang, D.; Zhang, D.D. The protective role of Nrf2 in streptozotocin-induced diabetic nephropathy. Diabetes 2010, 59, 850-860. [CrossRef] [PubMed]

7. Yoh, K.; Hirayama, A.; Ishizaki, K.; Yamada, A.; Takeuchi, M.; Yamagishi, S.; Morito, N.; Nakano, T.; Ojima, M.; Shimohata, H.; et al. Hyperglycemia induces oxidative and nitrosative stress and increases renal functional impairment in Nrf2-deficient mice. Genes Cells 2008, 13, 1159-1170. [CrossRef] [PubMed]

8. Xue, M.; Qian, Q.; Adaikalakoteswari, A.; Rabbani, N.; Babaei-Jadidi, R.; Thornalley, P.J. Activation of NF-E2-related factor-2 reverses biochemical dysfunction of endothelial cells induced by hyperglycemia linked to vascular disease. Diabetes 2008, 57, 2809-2817. [CrossRef] [PubMed]

9. Luo, Z.F.; Qi, W.; Feng, B.; Mu, J.; Zeng, W.; Guo, Y.H.; Pang, Q.; Ye, Z.L.; Liu, L.; Yuan, F.H. Prevention of diabetic nephropathy in rats through enhanced renal antioxidative capacity by inhibition of the proteasome. Life Sci. 2011, 88, 512-520. [CrossRef] [PubMed]

10. Zheng, H.; Whitman, S.A.; Wu, W.; Wondrak, G.T.; Wong, P.K.; Fang, D.; Zhang, D.D. Therapeutic potential of Nrf2 activators in streptozotocin-induced diabetic nephropathy. Diabetes 2011, 60, 3055-3066. [CrossRef] [PubMed]

11. Jurowski, K.; Szewczyk, B.; Nowak, G.; Piekoszewski, W. Biological consequences of zinc deficiency in the pathomechanisms of selected diseases. J. Biol. Inorg. Chem. 2014, 19, 1069-1079. [CrossRef] [PubMed]

12. Shen, H.; Oesterling, E.; Stromberg, A.; Toborek, M.; MacDonald, R.; Hennig, B. Zinc deficiency induces vascular pro-inflammatory parameters associated with NF-kB and PPAR signaling. J. Am. Coll. Nutr. 2008, 27, 577-587. [CrossRef] [PubMed]

13. Cortese, M.M.; Suschek, C.V.; Wetzel, W.; Kroncke, K.D.; Kolb-Bachofen, V. Zinc protects endothelial cells from hydrogen peroxide via Nrf2-dependent stimulation of glutathione biosynthesis. Free Radic. Biol. Med. 2008, 44, 2002-2012. [CrossRef] [PubMed]

14. Mehta, A.J.; Joshi, P.C.; Fan, X.; Brown, L.A.; Ritzenthaler, J.D.; Roman, J.; Guidot, D.M. Zinc supplementation restores PU.1 and Nrf2 nuclear binding in alveolar macrophages and improves redox balance and bacterial clearance in the lungs of alcohol-fed rats. Alcohol. Clin. Exp. Res. 2011, 35, 1519-1528. [CrossRef] [PubMed]

15. Wang, S.; Luo, M.; Zhang, Z.; Gu, J.; Chen, J.; Payne, K.M.; Tan, Y.; Wang, Y.; Yin, X.; Zhang, X.; et al. Zinc deficiency exacerbates while zinc supplement attenuates cardiac hypertrophy in high-fat diet-induced obese mice through modulating p38 MAPK-dependent signaling. Toxicol. Lett. 2016, 258, 134-146. [CrossRef] [PubMed]

16. Liang, T.; Zhang, Q.; Sun, W.; Xin, Y.; Zhang, Z.; Tan, Y.; Zhou, S.; Zhang, C.; Cai, L.; Lu, X.; et al. Zinc treatment prevents type 1 diabetes-induced hepatic oxidative damage, endoplasmic reticulum stress, and cell death, and even prevents possible steatohepatitis in the OVE26 mouse model: Important role of metallothionein. Toxicol. Lett. 2015, 233, 114-124. [CrossRef] [PubMed] 
17. Li, B.; Cui, W.; Tan, Y.; Luo, P.; Chen, Q.; Zhang, C.; Qu, W.; Miao, L.; Cai, L. Zinc is essential for the transcription function of Nrf2 in human renal tubule cells in vitro and mouse kidney in vivo under the diabetic condition. J. Cell. Mol. Med. 2014, 18, 895-906. [CrossRef] [PubMed]

18. Zhong, W.; Zhao, Y.; Sun, X.; Song, Z.; McClain, C.J.; Zhou, Z. Dietary zinc deficiency exaggerates ethanol-induced liver injury in mice: Involvement of intrahepatic and extrahepatic factors. PLoS ONE 2013, 8, e76522. [CrossRef] [PubMed]

19. Chen, M.D.; Lin, P.Y. Zinc-induced hyperleptinemia relates to the amelioration of sucrose-induced obesity with zinc repletion. Obes. Res. 2000, 8, 525-529. [CrossRef] [PubMed]

20. Marreiro, D.N.; Fisberg, M.; Cozzolino, S.M. Zinc nutritional status and its relationships with hyperinsulinemia in obese children and adolescents. Biol. Trace Elem. Res. 2004, 100, 137-149. [CrossRef]

21. Basaki, M.; Saeb, M.; Nazifi, S.; Shamsaei, H.A. Zinc, copper, iron, and chromium concentrations in young patients with type 2 diabetes mellitus. Biol. Trace Elem. Res. 2012, 148, 161-164. [CrossRef] [PubMed]

22. Jansen, J.; Rosenkranz, E.; Overbeck, S.; Warmuth, S.; Mocchegiani, E.; Giacconi, R.; Weiskirchen, R.; Karges, W.; Rink, L. Disturbed zinc homeostasis in diabetic patients by in vitro and in vivo analysis of insulinomimetic activity of zinc. J. Nutr. Biochem. 2012, 23, 1458-1466. [CrossRef] [PubMed]

23. Kazi, T.G.; Afridi, H.I.; Kazi, N.; Jamali, M.K.; Arain, M.B.; Jalbani, N.; Kandhro, G.A. Copper, chromium, manganese, iron, nickel, and zinc levels in biological samples of diabetes mellitus patients. Biol. Trace Elem. Res. 2008, 122, 1-18. [CrossRef] [PubMed]

24. Oh, H.M.; Yoon, J.S. Glycemic control of type 2 diabetic patients after short-term zinc supplementation. Nutr. Res. Pract. 2008, 2, 283-288. [CrossRef] [PubMed]

25. Jayawardena, R.; Ranasinghe, P.; Galappatthy, P.; Malkanthi, R.; Constantine, G.; Katulanda, P. Effects of zinc supplementation on diabetes mellitus: A systematic review and meta-analysis. Diabetol. Metab. Syndr. 2012, 4, 13. [CrossRef] [PubMed]

26. Kim, H.J.; Vaziri, N.D. Contribution of impaired Nrf2-Keap1 pathway to oxidative stress and inflammation in chronic renal failure. Am. J. Physiol. Renal Physiol. 2010, 298, F662-F671. [CrossRef] [PubMed]

27. Suzuki, M.; Betsuyaku, T.; Ito, Y.; Nagai, K.; Nasuhara, Y.; Kaga, K.; Kondo, S.; Nishimura, M. Down-regulated NF-E2-related factor 2 in pulmonary macrophages of aged smokers and patients with chronic obstructive pulmonary disease. Am. J. Respir. Cell. Mol. Biol. 2008, 39, 673-682. [CrossRef] [PubMed]

28. Cui, W.; Bai, Y.; Miao, X.; Luo, P.; Chen, Q.; Tan, Y.; Rane, M.J.; Miao, L.; Cai, L. Prevention of diabetic nephropathy by sulforaphane: Possible role of nrf2 upregulation and activation. Oxid. Med. Cell Longev. 2012, 2012, 821936. [CrossRef] [PubMed]

29. Khullar, M.; Al-Shudiefat, A.A.; Ludke, A.; Binepal, G.; Singal, P.K. Oxidative stress: A key contributor to diabetic cardiomyopathy. Can. J. Physiol. Pharmacol. 2010, 88, 233-240. [CrossRef] [PubMed]

30. Huang, W.; Bansode, R.R.; Bal, N.C.; Mehta, M.; Mehta, K.D. Protein kinase CBETA deficiency attenuates obesity syndrome of ob/ob mice by promoting white adipose tissue remodeling. J. Lipid Res. 2012, 53, 368-378. [CrossRef] [PubMed]

31. Cao, L.; Qin, X.; Peterson, M.R.; Haller, S.E.; Wilson, K.A.; Hu, N.; Lin, X.; Nair, S.; Ren, J.; He, G. CARD9 knockout ameliorates myocardial dysfunction associated with high fat diet-induced obesity. J. Mol. Cell. Cardiol. 2016, 92, 185-195. [CrossRef] [PubMed]

32. Bertin, J.; Guo, Y.; Wang, L.; Srinivasula, S.M.; Jacobson, M.D.; Poyet, J.L.; Merriam, S.; Du, M.Q.; Dyer, M.J.; Robison, K.E.; et al. CARD9 is a novel caspase recruitment domain-containing protein that interacts with BCL10/CLAP and activates NF-кB. J. Biol. Chem. 2000, 275, 41082-41086. [CrossRef] [PubMed]

33. Marko, L.; Henke, N.; Park, J.K.; Spallek, B.; Qadri, F.; Balogh, A.; Apel, I.J.; Oravecz-Wilson, K.I.; Choi, M.; Przybyl, L.; et al. Bcl10 mediates angiotensin II-induced cardiac damage and electrical remodeling. Hypertension 2014, 64, 1032-1039. [CrossRef] [PubMed]

34. Hsu, Y.M.; Zhang, Y.; You, Y.; Wang, D.; Li, H.; Duramad, O.; Qin, X.F.; Dong, C.; Lin, X. The adaptor protein CARD9 is required for innate immune responses to intracellular pathogens. Nat. Immunol. 2007, 8, 198-205. [CrossRef] [PubMed]

35. Han, J.; Ulevitch, R.J. Limiting inflammatory responses during activation of innate immunity. Nat. Immunol. 2005, 6, 1198-1205. [CrossRef] [PubMed]

36. Dong, C.; Davis, R.J.; Flavell, R.A. MAP kinases in the immune response. Annu. Rev. Immunol. 2002, 20, 55-72. [CrossRef] [PubMed] 
37. Ruland, J. CARD9 signaling in the innate immune response. Ann. N. Y. Acad. Sci. 2008, 1143, 35-44. [CrossRef] [PubMed]

38. Ren, J.; Yang, M.; Qi, G.; Zheng, J.; Jia, L.; Cheng, J.; Tian, C.; Li, H.; Lin, X.; Du, J. Proinflammatory protein CARD9 is essential for infiltration of monocytic fibroblast precursors and cardiac fibrosis caused by Angiotensin II infusion. Am. J. Hypertens. 2011, 24, 701-707. [CrossRef] [PubMed]

39. Cai, L.; Wang, Y.; Zhou, G.; Chen, T.; Song, Y.; Li, X.; Kang, Y.J. Attenuation by metallothionein of early cardiac cell death via suppression of mitochondrial oxidative stress results in a prevention of diabetic cardiomyopathy. J. Am. Coll. Cardiol. 2006, 48, 1688-1697. [CrossRef] [PubMed]

40. Liang, Q.; Carlson, E.C.; Donthi, R.V.; Kralik, P.M.; Shen, X.; Epstein, P.N. Overexpression of metallothionein reduces diabetic cardiomyopathy. Diabetes 2002, 51, 174-181. [CrossRef] [PubMed]

41. Matsushima, S.; Kinugawa, S.; Ide, T.; Matsusaka, H.; Inoue, N.; Ohta, Y.; Yokota, T.; Sunagawa, K.; Tsutsui, H. Overexpression of glutathione peroxidase attenuates myocardial remodeling and preserves diastolic function in diabetic heart. Am. J. Physiol. Heart Circ. Physiol. 2006, 291, H2237-2245. [CrossRef] [PubMed]

42. Shen, X.; Zheng, S.; Metreveli, N.S.; Epstein, P.N. Protection of cardiac mitochondria by overexpression of MnSOD reduces diabetic cardiomyopathy. Diabetes 2006, 55, 798-805. [CrossRef] [PubMed]

43. Wang, Y.; Zhang, Z.; Guo, W.; Sun, W.; Miao, X.; Wu, H.; Cong, X.; Wintergerst, K.A.; Kong, X.; Cai, L. Sulforaphane reduction of testicular apoptotic cell death in diabetic mice is associated with the upregulation of Nrf2 expression and function. Am. J. Physiol. Endocrinol. Metab. 2014, 307, E14-E23. [CrossRef]

44. Zhang, Z.; Wang, S.; Zhou, S.; Yan, X.; Wang, Y.; Chen, J.; Mellen, N.; Kong, M.; Gu, J.; Tan, Y.; et al. Sulforaphane prevents the development of cardiomyopathy in type 2 diabetic mice probably by reversing oxidative stress-induced inhibition of LKB1/AMPK pathway. J. Mol. Cell. Cardiol. 2014, 77, 42-52. [CrossRef] [PubMed]

(C) 2017 by the authors. Licensee MDPI, Basel, Switzerland. This article is an open access article distributed under the terms and conditions of the Creative Commons Attribution (CC BY) license (http:/ / creativecommons.org/licenses/by/4.0/). 